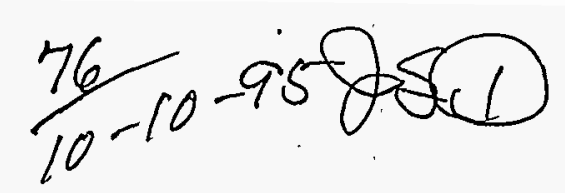

\title{
Waste Management and the Land Disposal Restriction Storage Prohibition
}

BACKGROUND: RCRA Sect 3004(j) prohibits storage of wastes that have been prohibited from land disposal, unless that storage is for the purpose of accumulating sufficient quantities of hazardous wastes to facilitate proper recovery, treatment, or disposal. The intent of Congress in enacting this provision was to prevent long-term storage as a means of circumventing treatment requirements. This requirement was incorporated as part of the Land Disposal Restriction (LDR) regulations (40 CFR 268.50). Under the LDR storage prohibition, facilities may only store restricted wastes in containers and tanks (provided that each container or tank is clearly marked to identify its contents and the date the hazardous waste entered storage). As stated in the Third Third LDR rule, storage of prohibited waste is only allowed in non-land based storage units (i.e., tanks and containers) since land-based storage is a form of disposal (55 FR 22673).

The EPA has recognized that generators and storers of radioactive mixed waste (RMW) may find it impossible to comply with the section $30040)$ storage prohibition in cases where no available treatment capacity exists (56 FR 42731). Additionally, under the current regulatory interpretation, there is no provision that would allow for storage of wastes for which treatment capacity and capability are not available, even where capacity is legitimately being developed. Thus, a central issue regarding the LDR storage prohibition is: "When does the storage prohibition apply to wastes?"

Under the LDR program, restricted wastes that are disposed of, or placed into storage before an LDR effective date, are not subject to the LDR requirements. However; if such wastes are removed from a storage or disposal site after the effective date, such wastes would be subject to LDR requirements. With this in mind, it is important to recognize the types of waste management practices that would trigger the LDR requirements for wastes placed in storage prior to an applicable LDR effective date. The purpose of this information brief is to clarify what waste management practices constitute removal from storage:

STATUTES: Resource Conservation and Recovery Act (RCRA) Sects. 3004(d) through (k)

REGULATIONS: $\quad 40$ CFR Parts 148 and 268 


\section{Are wastes that are placed into storage prior to an applicable effective date sub- ject to the LDR storage prohibition?}

No. The EPA has stated that it interprets the LDR requirements as applying prospectively to restricted hazardous wastes. Therefore, the prohibitions on storage of prohibited wastes apply only to wastes placed in storage after an LDR effective date. Wastes placed in storage prior to the applicable effective date would not be subject to the prohibition on storage. However, once such wastes are removed from storage, they must be managed in compliance with the LDR storage prohibition, applicable LDR treatment provisions, and other restrictions.

\section{What constitutes storage under RCRA?}

To understand what activities constitute removal from storage, one must first understand the definition of the term storage under RCRA. Storage is defined under 40 CFR 260.10 as "the holding of hazardous wastes for a temporary period, at the end of which the hazardous waste is treated, disposed of, or stored elsewhere."

\section{What factors should be considered in determining whether specific waste management activities performed at DOE facilities constiłute removal from storage?}

Considering the RCRA definition of storage, treatment or disposal of waste would clearly constitute removal from storage and trigger the LDRs. Storing wastes elsewhere would also constitute removal from storage and trigger the LDRs. Elsewhere may be interpreted as a place that is not on-site. On-site is contiguous property, or non-contiguous property connected by a right-of-way and owned by the same person ( 40 CFR 260.10). Therefore, as long as hazardous and radioactive mixed wastes stored prior to the applicable LDR effective date, are not stored off-site, treated, or disposed of, the wastes are not removed from storage and the LDRs are not triggered.

\section{Does transport of waste from one stor- age unit to another at the same facility constitute removal from storage?}

No. Transporting stored wastes from one storage unit to another located on one's property (i.e., onsite), provided it is neither disposed of nor treated, . would not be removal from storage, and thus would not trigger the LDRs. However, transport of stored waste to an off-site facility for continued storage would constitute removal from storage and thus trigger the LDR's.

In the case of waste placed in storage prior to the applicable LDR effective date, does the transfer of such waste from one tank to another located on the facility constitute removal from storage?

No. The wastes have not been stored elsewhere, treated, or disposed of. Therefore, the waste has not been removed from storage and the transfer of wastes from one tank to another tank on-site (e.g., transfer via tank truck) does not trigger the LDRs.

Likewise, the transfer of waste from one tank to another tank within the same-tank farm, via piping that interconnects the tanks, does not constitute removal from storage because the waste is not stored off-site, treated, or disposed of. Çonsequently, the LDRs are not triggered. However, if prohibited wastes are added to either tank after the applicable effective date, the receiving tank would be subject to the storage prohibition.

\section{Does repackaging of containers to en- sure safe waste storage constitute re- moval from storage?}

The answer to the question depends on whether the waste is repackaged on-site or off-site. Because the act of repackaging is neither treatment nor disposal, the substantive issue is whether the management is on-site. If the waste is repackaged at the storage facility where it is managed or at another unit on-site, then such repackaging does not constitute removal from storage. If, however, the waste is transported off-site to another facility for repackaging, such actions would constitute storage elsewhere and, therefore, trigger the storage prohibition.

Does the transfer of waste, which was in storage prior to the applicable LDR effective date, through a closed system from a storage unit to a treatment unit constitute removal from storage?

Yes. Storage, by definition, ends when a waste is treated or disposed of. Therefore, while restricted wastes that are placed into storage before the applicable LDR effective date are not subject to the LDRs, transfer of such wastes from a tank or con- 


\section{DISCLAIMER}

This report was prepared as an account of work sponsored by an agency of the United States Government. Neither the United States Government nor any agency thereof, nor any of their employees, make any warranty, express or implied, or assumes any legal liability or responsibility for the accuracy, completeness, or usefulness of any information, apparatus, product, or process disclosed, or represents that its use would not infringe privately owned rights. Reference herein to any specific commercial product, process, or service by trade name, trademark, manufacturer, or otherwise does not necessarily constitute or imply its endorsement, recommendation, or favoring by the United States Government or any agency thereof. The views and opinions of authors expressed herein do not necessarily state or reflect those of the United States Government or any agency thereof. 


\section{DISCLAIMER}

Portions of this document may be illegible in electronic image products. Images are produced from the best available original document. 
tainer to a treatment unit after the effective date constitutes removal from storage. Subsequent placement of the treated waste in or on the land would be subject to LDR requirements.

On the other hand, the waste remaining in the storage unit after the other portion is transferred to a treatment system has not been removed from storage by storing elsewhere, treating, or disposing. Therefore, the waste remaining in the unit is not subject to LDR requirements.

\section{Do the practices of mixing, blending, aerating or otherwise manipulating waste within a tank to keep it homoge- neous (i.e., to prevent stratification) constitute removal from storage?}

In general, no. Treatment is defined as anything that changes the physical, chemical, or biological properties of a waste (40 CFR 261.10). Mixing and blending of a waste do not normally change the physical state or the chemical and biological properties of the waste, nor do these practices reduce the volume or toxicity of the waste. Thus, mixing and blending to prevent stratification are not treatment. Because the waste has not been stored elsewhere, treated, or disposed of, it has not been removed from storage. Aerating waste may or may not be considẹred treatment depending on whether the aeration process changes the physical, chemical, or biological properties of the waste:

Does the taking of wastes out of storage for the purpose of pretreatment (e.g.,'dewatering, drying, etc.) constitute removal from storage?

Yes. Pretreatment practices constitute a form of treatment since the physical, chemical, and/or biological characteristics of the wastes are likely changed. Where pretreatment is conducted (on wastes placed into storage prior to an applicable LDR effective date) in order to improve the form of a waste destined for further storage, such pretreatment would be considered removal from storage, and consequently the pretreated wastes would be subject to the LDR requirements. If, however, a waste is pretreated and placed into storage solely for the purpose of accumulating sufficient wastes as necessary to facilitate proper recovery or treatment in accordance with LDR treatment standards, such storage would be in compliance with the storage prohibition.
If a sample of waste has been removed from a storage unit for waste analysis, is that sample considered removed from storage and thus subject to LDR requirements?

Under 40 CFR 261.4(d), samples that are collected for the sole purpose of testing to determine the waste's characteristics or composition are exempted from the LDRs. In order to qualify for this exemption, the samples must be shipped in compliance with applicable shipping requirements (e.g., U.S. Department of Transportation and U.S. Postal Service requirements).

Once the sample analysis is completed, this exemption would continue to apply to any remaining untested portion of the sample provided it is promptly returned to the sample collector from whom it was obtained. If the tested sample returned to the generator (i.e., sample collector) is not stored by the generator for a specific purpose (i.e., enforcement action), and analysis has shown the tested waste to be an LDR waste (i.e., spent solvent, dioxin, California List, etc.) the tested portion is considered to have been removed from storage and the LDRs would apply.

On the other hand, when the untested portion of the sample is returned to the collector, the determination of whether the sample is considered removed from storage depends on what the sample collector does with the sample. If it is returned to the original storage unit, it has not been removed from storage and the LDRs do not apply. If it is placed in a storage unit with wastes other than those that were originally sampled, or is treated or disposed of, the sample has been removed from storage and the LDRs apply. In either case, the waste remaining in the storage unit from which the sample was taken has not been removed from storage and is not subject to LDR requirements.

Does "topping off" of a waste container with other wastes constitute removal from storage if the additional waste was initially placed in.storage prior to the applicable LDR effective date?

No, provided that (1) the added waste will not change the chemical, physical, or biological properties of the waste in the receiving container and (2) the additional waste has itself not been removed from storage under the storage elsewhere criterion discussed above. If the added waste has been removed from storage or generated since the applica- 
ble effective date, then all of the waste in that tank or container would be considered to have been removed from storage and therefore would be subject to the LDRs.

\section{How is the term active management de- fined under implementing regulations, and what does it mean relative to the LDRs and the concept of removal from storage?}

The term active management is not defined in rule, but EPA discussed its meaning in the September 1,1989 , notice on the mining waste exclusion (54 FR 36597). In the rule active management is used as a criterion in determining whether a solid waste management unit is subject to Subtitle C requirements.

This is different from asking whether a hazardous waste is subject to the LDRs. Although the term is sometimes used by environmental personnel in reference to practices that subject wastes to the LDRs, EPA has not clarified its meaning relative to the LDRs. For clarity of communication, the term is best avoided in discussions of the management practices that constitute removal from storage and thus trigger the LDR requirements.

\section{How do the concepts of removal from storage and placement into a land dis- posal unit differ and compare?}

The concepts of removal from storage and placement into the land apply to different scenarios and should not be confused. Removal from storage is used to define what actions constitute removing wastes from a storage unit (thereby, triggering the LDRs). This concept is most important in waste management contexts, as seen in the above examples.

Placement, on the other hand, refers to actions in which restricted hazardous wastes are placed in or on the land (e.g., in landfills, surface impoundments, etc.). RCRA-regulated hazardous wastes that are placed in land-based units (i.e., land disposed) are subject to the applicable LDR standards. The concept of placement is most relevant to environmental restoration activities and has been well-defined by EPA for CERCLA actions.

Given that generators and storers of mixed hazardous wastes may find it impossible to comply with the LDR storage prohibition if there is no available treatment or disposal capacity for these wastes, how does EPA intend to enforce the storage prohibition?

On August 29, 1991, EPA published a policy pertaining to the civil enforcement priority that it will assign to the LDR storage prohibition violations at facilities that generate radioactive mixed waste (56 FR 42730). Under this policy, small volume generators who are operating their storage facilities in an environmentally responsible manner are considered a reduced enforcement priority. This enforcement policy applies only to those facilities that generate less than 1000 cubic feet of prohibited radioactive mixed waste per year. While this limit would exclude nearly all DOE facilities, the EPA policy points to several indicators of environmentally responsible operation, that it will consider in determining its enforcement priority under the LDR storage prohibition. Among the indicators are:

whether the facility is in compliance with all other RCRA storage facility requirements;

whether the facility has kept records of its mixed wastes, including sources, waste codes, generation rates and volumes in storage;

whether the facility has developed a mixed waste minimization plan where possible;

whether the facility can document its attempts to ascertain the availability of treatment capacity for its wastes; and

whether the facility has cooperated with EPA and NRC in providing complete and accurate information about its radioactive mixed wastes upon request.

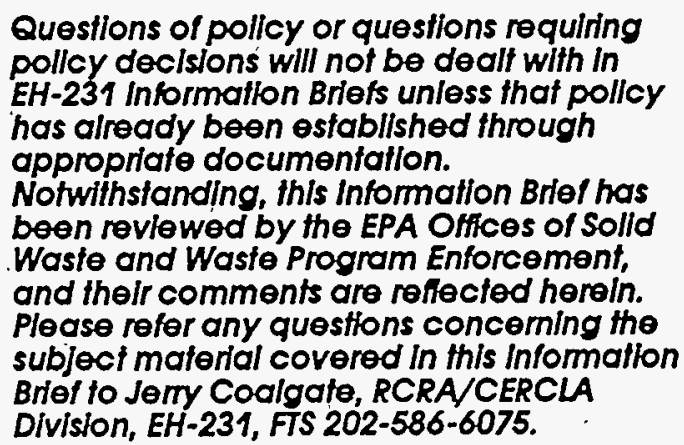
pollcy declsions will not be dealt with in EH-231 information Briets unless that pollcy has already been established through appropriate documentailon. Notwithstanding, this information Bitel has been reviewed by the EPA Offices of Solid Waste and Wasfe Program Enforcement, and their comments are refrected herein. Please refer any questions concerning the subjeci maferial covered in this information Brief to Jemy Coalgate, RCRA/CERCLA Division, EH-231, FTS 202-586-6075. 